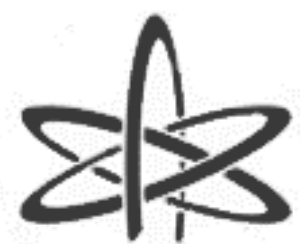

BJRS
BRAZILIAN JOURNAL

$\mathrm{OF}$

RADIATION SCIENCES

06-03 (2018) 01-13

\title{
Evaluation of some dosimetric properties of a dedicated plane parallel ionization chamber for radiotherapy electron beams
}

\author{
J. O. Silva' ; F. B. C. Nonato ${ }^{\text {b }}$ F. G. A. Sampaio ${ }^{\text {c }}$ L. V. E. Caldas ${ }^{\mathrm{d}}$ \\ ${ }^{a}$ Universidade Federal de Goiás/Instituto de Física, Campus Samambaia, Goiânia, GO, Brazil \\ ${ }^{b}$ Centro Universitário Anhanguera de Santo André, Santo André, SP, Brazil \\ ${ }^{c}$ Instituto de Radioterapia e Megavoltagem, Ribeirão Preto, SP, Brazil \\ ${ }^{d}$ Instituto de Pesquisas Energéticas e Nucleares (IPEN-CNEN/SP), São Paulo, SP, Brazil \\ jonas.silva@ufg.br
}

\begin{abstract}
Ionization chambers are the reference detectors for electron beam dosimetry. In this paper a dedicated radiotherapy plane parallel ionization chamber manufactured with low cost materials is presented for dosimetry in electron beams. The ionization chamber tested has a sensitive volume of $0.4 \mathrm{~cm}^{3}$. Both the collecting electrode and the guard ring were painted with a homogeneous mixture of nail polish and graphite. The dedicated ionization chamber presented a linear response with electron absorbed dose within the range 0.5 to $8.0 \mathrm{~Gy}$, an increase of its response with the field size increasing, an angular dependence within $\pm 5^{\circ}$, as recommended by international standards, and a polarity effect of $\mathbf{0 . 7 8 \%}$ according to the field size. Considering the results obtained, it is possible to conclude that the plane parallel ionization chamber tested in this work presents potential use for electron beam dosimetry in clinical routine.
\end{abstract}

Keywords: ionization chambers, electron beams, radiation dosimetry, radiotherapy. 


\section{INTRODUCTION}

The most widespread use of ionizing radiation by humans is found in medical field applications. Among them, one of the major uses of radiation in medicine is in radiotherapy, that is applied to eliminate or inhibit the cancerous tumors by using high energy X-rays or electron beams (teletherapy). It is important to guarantee the maximum radiation dose to the disease and to avoid unnecessary irradiation of healthy tissues. This is accomplished with a well established dose planning followed by the radiation protection of patients and a high accuracy quality control program [1].

The dosimetry of electron beams in radiotherapy can be performed either by plane parallel or by cylindrical ionization chambers for any electron energy range $[2,3]$, but plane parallel ion chambers are mandatory for electron beam energies lower than $10 \mathrm{MeV}$ [3-5]. Ionization chambers are the reference detectors for electron beam dosimetry, and it is essential to apply correction factors to their response as for humidity, temperature and pressure, ion recombination and polarity changes [4-8].

At the Calibration Laboratory of IPEN the research group has developed several ionization chambers for radiation dosimetry in medical irradiation equipment (therapy and diagnostic energy range) and laboratory applications (as secondary standards) made with cheap accessible materials with high metrological performance [9-13].

The dedicated plane parallel ionization chamber utilized in this work has been characterized previously in standard electron and photon beams, as reported by Nonato et al. [10], and it uses a homogeneous mixture of nail polish and powdered graphite applied to a PMMA base as collecting electrode. It presents a polarity effect of $4 \%$ for LINAC electron beams with nominal energy of $6 \mathrm{MeV}$ and around $3 \%$ for $12 \mathrm{MeV}$ electron beams, both for the depth of $0.7 \mathrm{R}_{\mathrm{p}}$ (practical range in centimeters). These results on the polarity effect are less than the value of $5 \%$ for the polarity effect of the Advanced Markus ionization chamber when irradiated with electron beams with nominal energy of $4 \mathrm{MeV}$ [14]. However, the polarity effect is not a concern if the ion chamber is always utilized at the same conditions of polarity and tension [15]. Besides the polarity effect, other tests are necessary to evaluate its use in clinical electron beam dosimetry [16]. 
The ionization chamber investigated was the first one developed by the IPEN research group using the described mixture for the collecting electrode. The most common material utilized for the collecting electrodes of the IPEN ionization chambers was a uniformly spread graphite spray in various base types [11-13,17]. The mixture of colorless nail varnish and powered graphite was an alternative way for collecting electrode material because of its easy acquisition and application on a PMMA base with an excellent electrical conductivity [18].

The objective of this work was to verify the performance of the dedicated plane parallel ionization chamber in clinical dosimetry tests with high energy electron beams as linearity of the response with absorbed dose in a PMMA phantom, angular dependence, field size dependence and the polarity effect as a function of the field size in a PMMA water equivalent phantom.

\section{MATERIALS AND METHODS}

The ionization chamber tested in this work is a vented chamber with a sensitive volume of $0.4 \mathrm{~cm}^{3}$ and a distance of $0.2 \mathrm{~cm}$ between the electrodes. A scheme of this ionization chamber with its dimensions is presented in Figure 1. The chamber body, the collecting electrode and the guard ring are made of PMMA with a density of $1.17 \mathrm{~g} / \mathrm{cm}^{3}$. The collecting electrode and the guard ring were painted with a homogeneous mixture of colorless nail polish and powdered graphite. More details about how the painting of the mixture was applied can be found in [18].

Figure 1: Scheme of the ionization chamber utilized in this work adapted from Nonato [18]. 


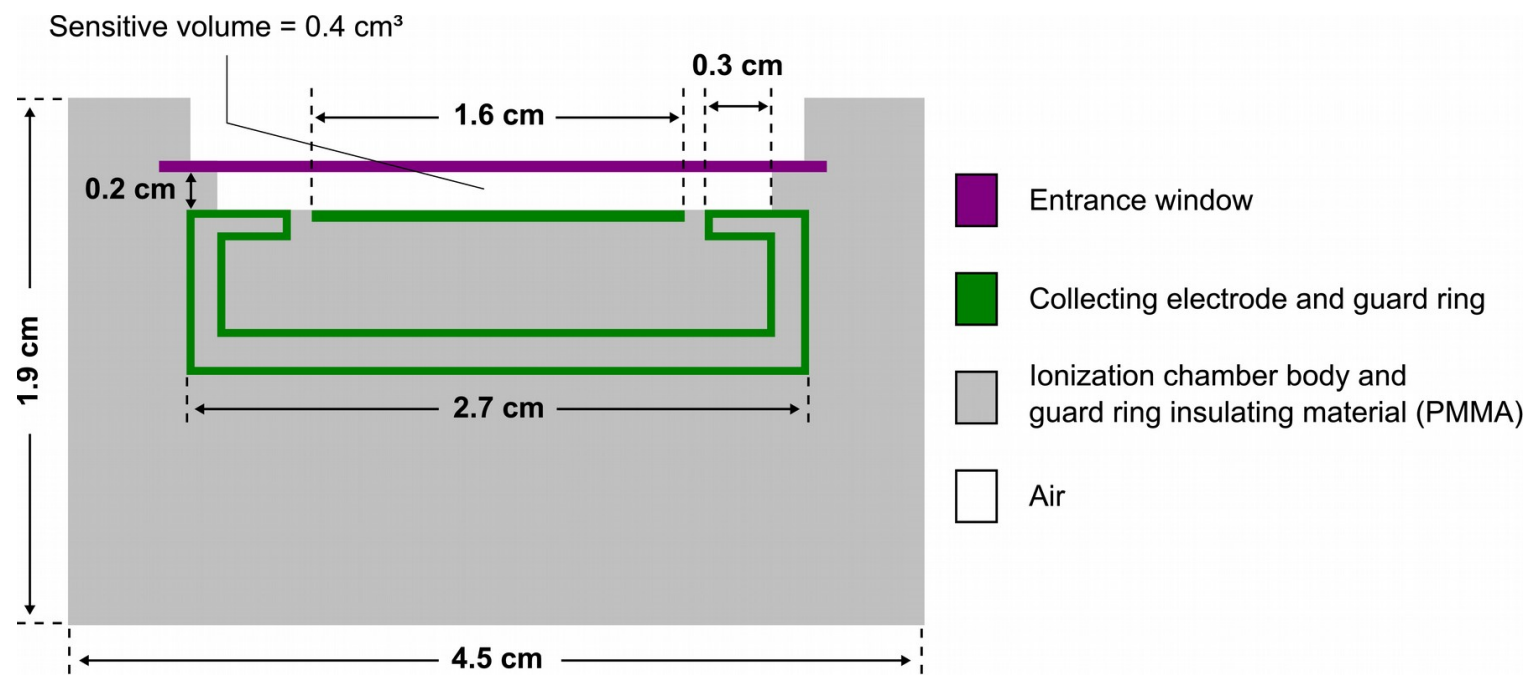

To establish the electric field, an aluminized polyester film with $1.87 \mathrm{mg} / \mathrm{cm}^{2}$ of superficial density was utilized as the entrance window. The primary characterization tests were made at the Calibration Laboratory (LCI) at IPEN/CNEN-SP [18].

A Siemens Primus linear accelerator at the Radiotherapy and Megavoltage Institute - IRMEV, Ribeirão Preto, Brazil, with electron beam energy of $7 \mathrm{MeV}$, was utilized as the irradiator system. A dose rate of $3 \mathrm{~Gy} / \mathrm{min}$, specified for dose to PMMA, and a source to surface distance of $100 \mathrm{~cm}$ were selected for all irradiations. The linear accelerator electron beams dosimetry was accomplished according to the IAEA protocol [5]. Measurements of linearity of the response with absorbed dose, angular dependence, field size dependence and the polarity effect as function of the field size were performed to investigate the ionization chamber response. The reference material for the absorbed dose was the PMMA.

A phantom made of various PMMA slab thicknesses with $30 \times 30 \mathrm{~cm}^{2}$ was utilized to localize the ionization chamber in relation to the central beam axis. A CNMC electrometer, model 11, serial 
number 4372, of the IRMEV, was utilized to polarize and to collect the readings of the ionization chamber. The measurements were corrected for the environmental standard conditions of temperature and pressure, as described in IAEA TRS 398 for this radiation detector type [5]. In Figure 2 is presented a general experimental setup scheme for the measurements performed in this work.

Figure 2: Diagram of the general experimental setup for the measurements obtained with the ionization chamber in high energy electron beams.

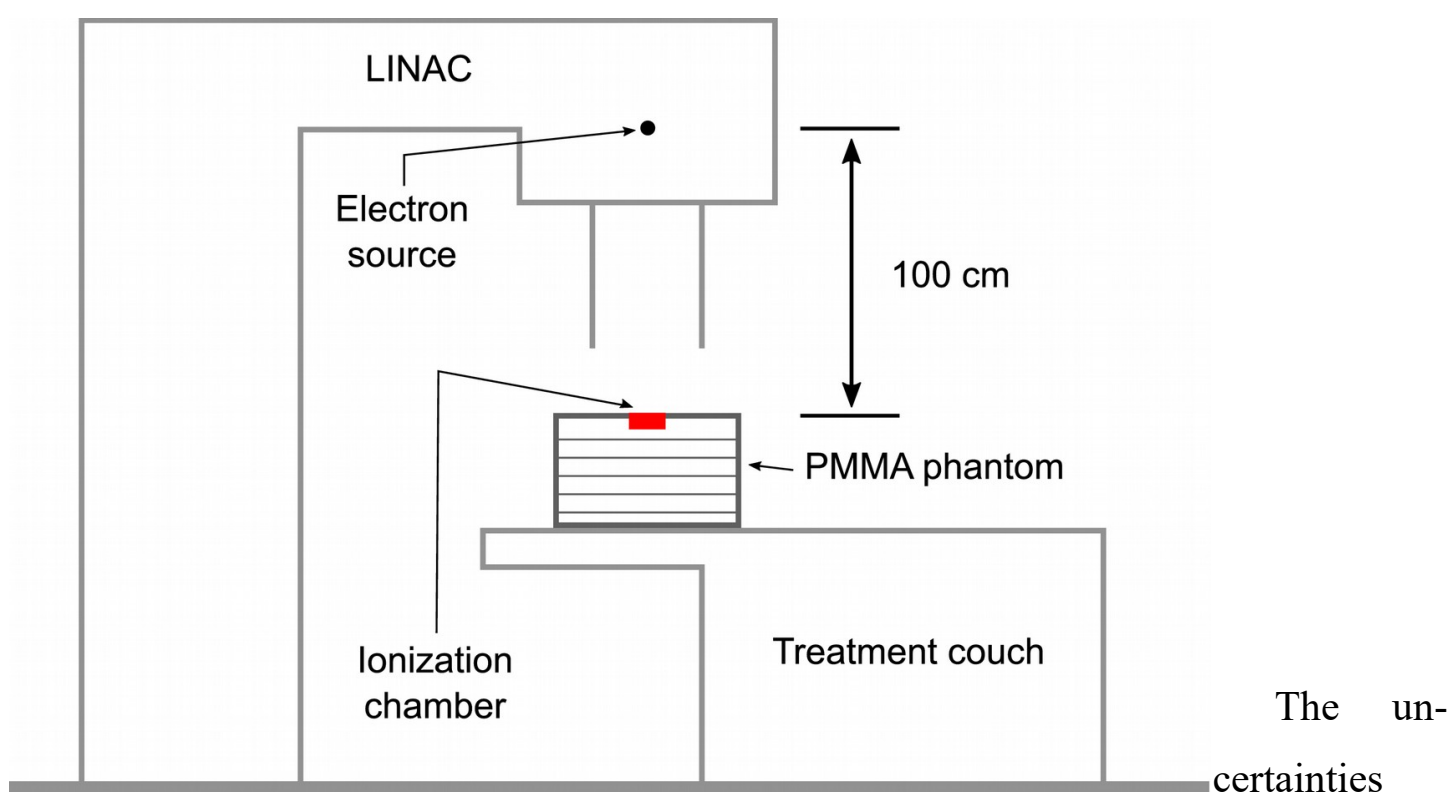

utilized in this work were from both types, A and B, as defined in the GUM [19]. For type A uncertainties the mean values and standard deviations from the measurements performed with the ionization chamber were considered. The resolutions of the CNMC electrometer and auxiliary equipment (thermometer and barometer) were considered for type B uncertainties.

\section{RESULTS AND DISCUSSION}

The ionization chamber was tested according to international recommendations $[4,5,16]$. The ionization chamber was pre-irradiated during 15 minutes before the irradiations to achieve response stability conditions [10]. The ionization chamber tested in this work presents a reproducible response in time with accuracy within $\pm 0.5 \%$ limit variation [18] as recommended in the IEC 
60731:2011 standard for reference-class dosimeters used in radiotherapy [16]. Other tests of response variation of the dedicated ionization chamber with time were presented previously [10].

The dedicated plane-parallel ionization chamber may be submitted to the maximum polarities of $\pm 400 \mathrm{~V}$, but the work tension of $+300 \mathrm{~V}$ was chosen because this value was applied during the ionization chamber calibration at IPEN [16].

\subsection{Linearity curve}

This ionization chamber presented a linear response in an absorbed dose range of 0 to 0.6 Gy when submitted to a ${ }^{90} \mathrm{Sr}+{ }^{90} \mathrm{Y}$ standard source in a source-chamber distance of $11 \mathrm{~cm} \mathrm{[10].} \mathrm{In} \mathrm{order}$ to verify the dedicated chamber response in a wider range, the linearity curve (response $\times$ absorbed dose) was obtained taking 3 measurements for each absorbed dose ranging from 0.5 Gy to 8.0 Gy for $7 \mathrm{MeV}$ electron beams. The measurements for this test were performed with a $10 \times 10 \mathrm{~cm}^{2}$ field size, and at the depth of maximum dose. The ionization chamber was located at a reference sourcechamber distance of $100 \mathrm{~cm}$, and was polarized with $+300 \mathrm{~V}$.

The linearity curve is presented in Figure 3 where each point represents the mean value of 3 measurements, each set of three measurements with a repeatability around $0.5 \%$. The correlation coefficient for the curve was calculated using the method of linear curve fitting based on leastsquares fit, and it was exactly 1.000 .

Figure 3: Linearity curve of the ionization chamber: response as function of the absorbed dose, using a $7 \mathrm{MeV}$ electron beam. The maximum uncertainty was $0.05 \%$, not visible in the figure.

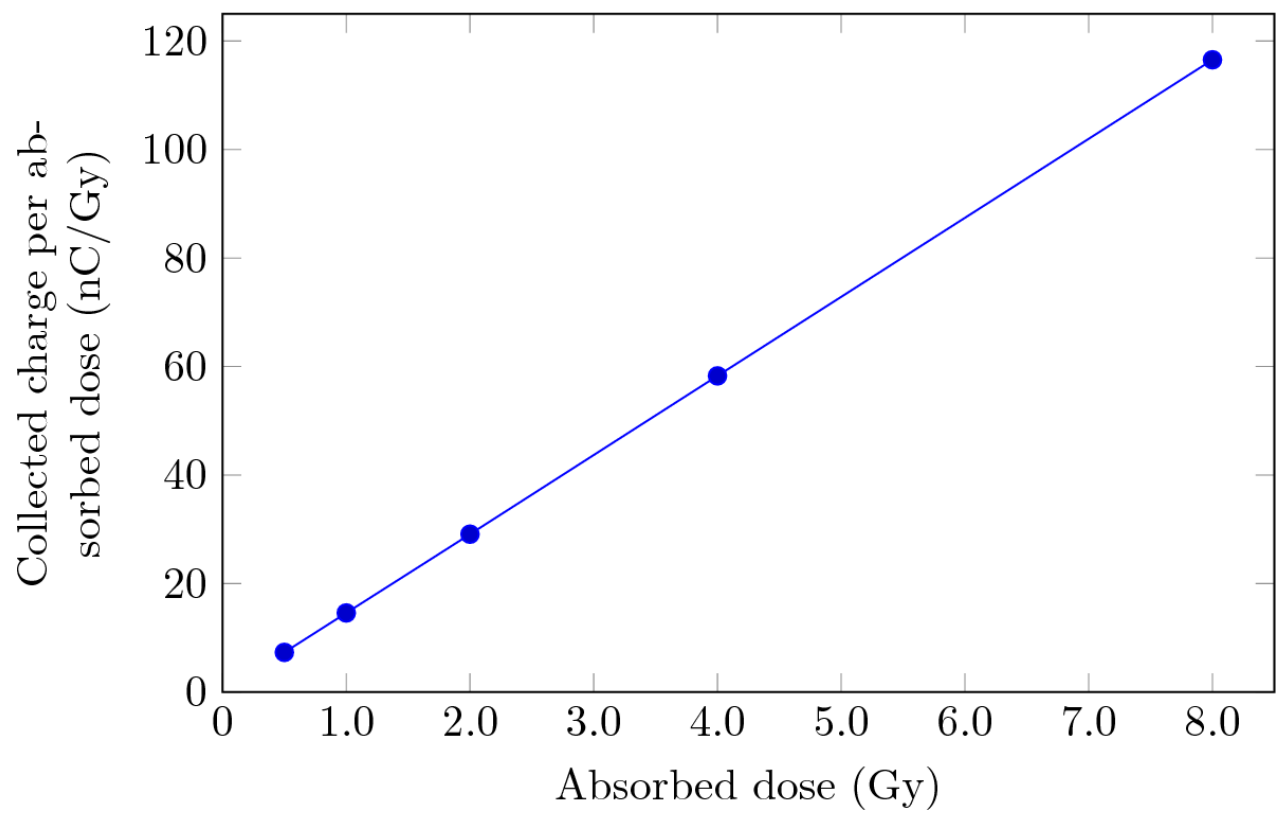




\subsection{Angular dependence}

The dependence of the ionization chamber response with the central axis angular orientation was verified in the angular dependence test. The ionization chamber entrance window was located in the PMMA phantom at the depth of maximum dose, at the reference distance of $100 \mathrm{~cm}$. The irradiations were performed in a $7 \mathrm{MeV}$ electron beam, for an absorbed dose of $1 \mathrm{~Gy}$ and a $10 \times 10 \mathrm{~cm}^{2}$ field, which was the smallest field size available for the electron beams utilized in the present work.

The radiation incident angle was changed from $0^{\circ}$ to $\pm 5^{\circ}$, in steps of $1^{\circ}$, in relation to the position of perpendicular incidence of the radiation beam axis. The clockwise orientation was taken as the positive one, and for each angle 3 measurements were carried out. In Figure 4 the ionization chamber performance in this test is presented, and each point represents the normalized response to the $0^{\circ}$ mean value. All the uncertainties presented are the overall uncertainties with $\mathrm{k}=2$. Figure 4 shows that the results are within the value of $\pm 1.0 \%$ for the tilt of $\pm 5^{\circ}$, as recommended by IEC [16].

Figure 4: Angular dependence test results for the ionization chamber when exposed to a

\section{$7 \mathrm{MeV}$ electron beam.}

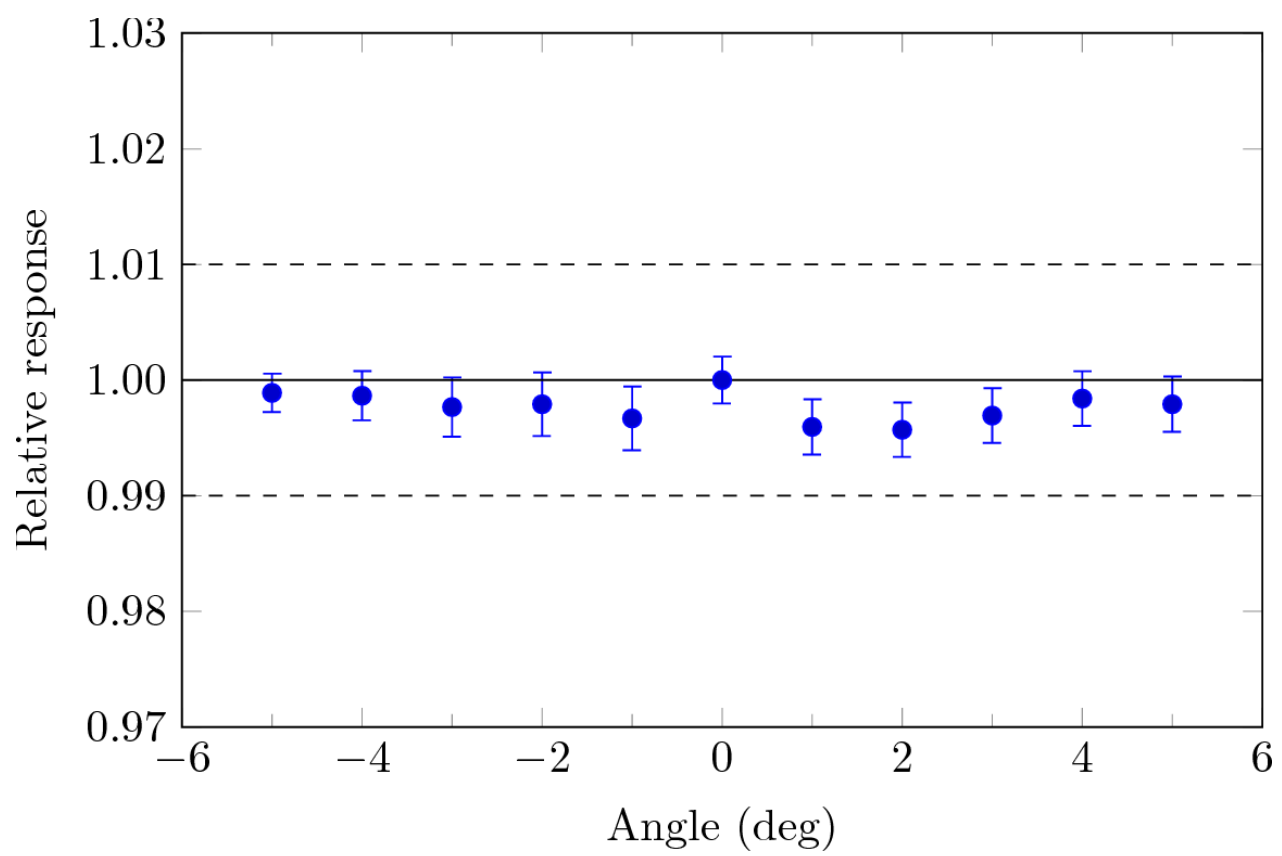




\subsection{Field size dependence}

The variation of the ionization chamber response with the amount of scattered radiation was verified in the field size dependence test for $7 \mathrm{MeV}$ electron beam. The detector was polarized with $+300 \mathrm{~V}$ and it was positioned at the depth of maximum dose in the PMMA phantom, at the center of the radiation field, $100 \mathrm{~cm}$ from the electron source. This test was performed for an absorbed dose value of 1 Gy delivered at the depth of maximum dose, where the chamber reference point was located. In this study, field sizes with areas of $10 \times 10,15 \times 15$ and $20 \times 20 \mathrm{~cm}^{2}$, defined by electron applicators, were applied, and the mean value of 3 measurements for each field size was normalized in relation to the $15 \times 15 \mathrm{~cm}^{2}$ field mean result. The results for this test are presented in Figure 5, in which an increase in the ionization chamber response according to the increase of field dimensions can be observed. This occurs due to the higher amount of lateral scattered radiation in a larger PMMA phantom surface. It can be seen that the limit of response variation for this test is within $\pm 2.0 \%$, as required by the IEC 60731 standard [16].

Figure 5: Field size dependence of the response of the ionization chamber utilized in this work for $7 \mathrm{MeV}$ electron beam. The fields are defined by electron applicators and the results were normalized to the mean result obtained for $15 \times 15 \mathrm{~cm}^{2}$ field.

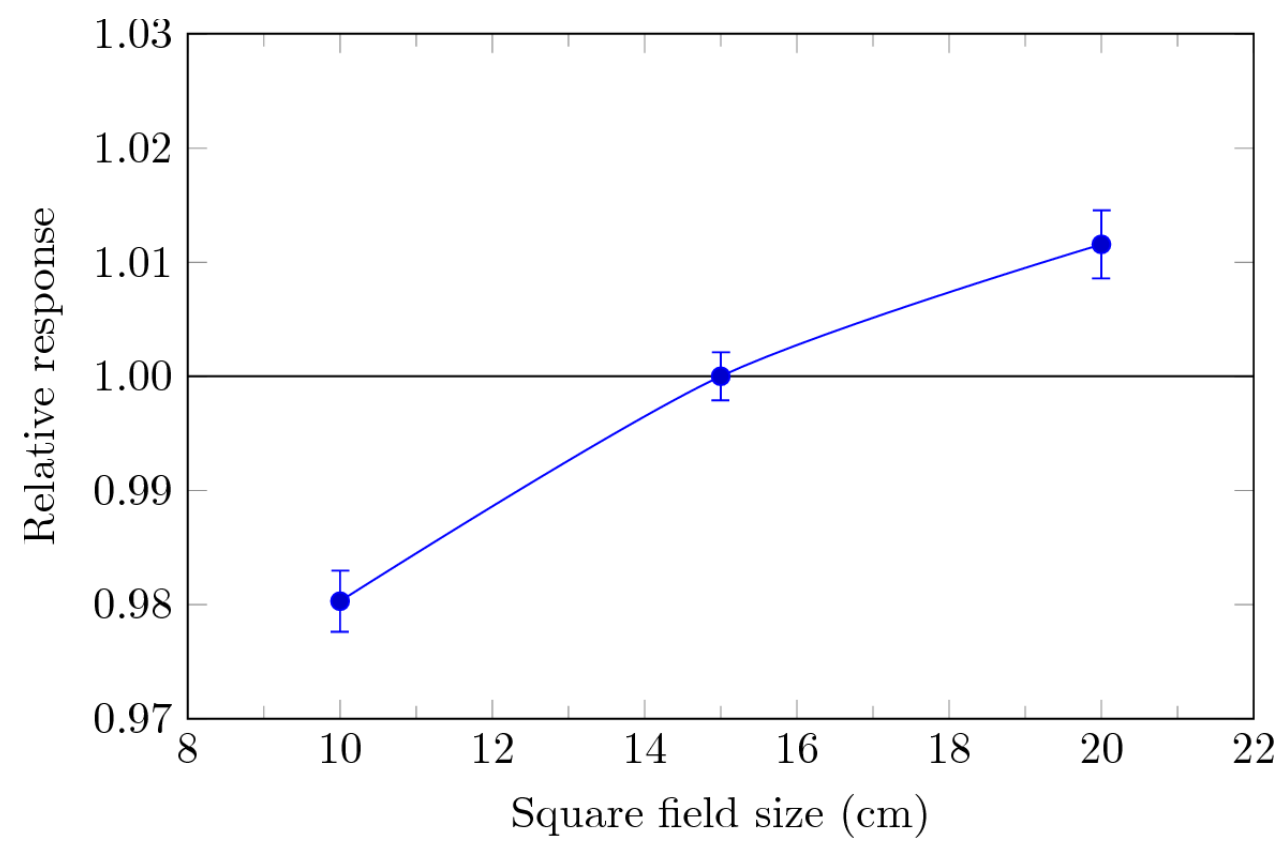




\subsection{The polarity effect as function of the field size}

For this analysis, the same setup applied to the field size dependence test was utilized. The ionization chamber was polarized with $\pm 300 \mathrm{~V}$, to obtain the polarity ratio $\left(\mathrm{Q}_{-} / \mathrm{Q}_{+}\right)$, and one more field size $\left(25 \times 25 \mathrm{~cm}^{2}\right)$ was added to this study. Figure 6 shows the polarity effect as function of the field size for the ionization chamber tested in the present study. The ionization chamber presents a field size dependence of $0.78 \%$ with the change of polarizing voltage over the entire measured range of field sizes.

It can be seen that when the field dimensions are increased the polarity effect increases too. The results obtained agree with those published by Ramsey et al. [20], except for the $25 \times 25 \mathrm{~cm}^{2}$ field that has a lower value in comparison with that related to the $20 \times 20 \mathrm{~cm}^{2}$ field. A similar behavior was obtained for the commercial plate-parallel PS033 chamber. It presented a field size dependence of the polarity effect around $0.5 \%$ over a field size range from $4 \times 4 \mathrm{~cm}^{2}$ to $25 \times 25 \mathrm{~cm}^{2}$, when irradiated with a $6 \mathrm{MeV}$ electron beam [21].

Figure 6: Field size dependence of the polarity effect for the dedicated ionization chamber.

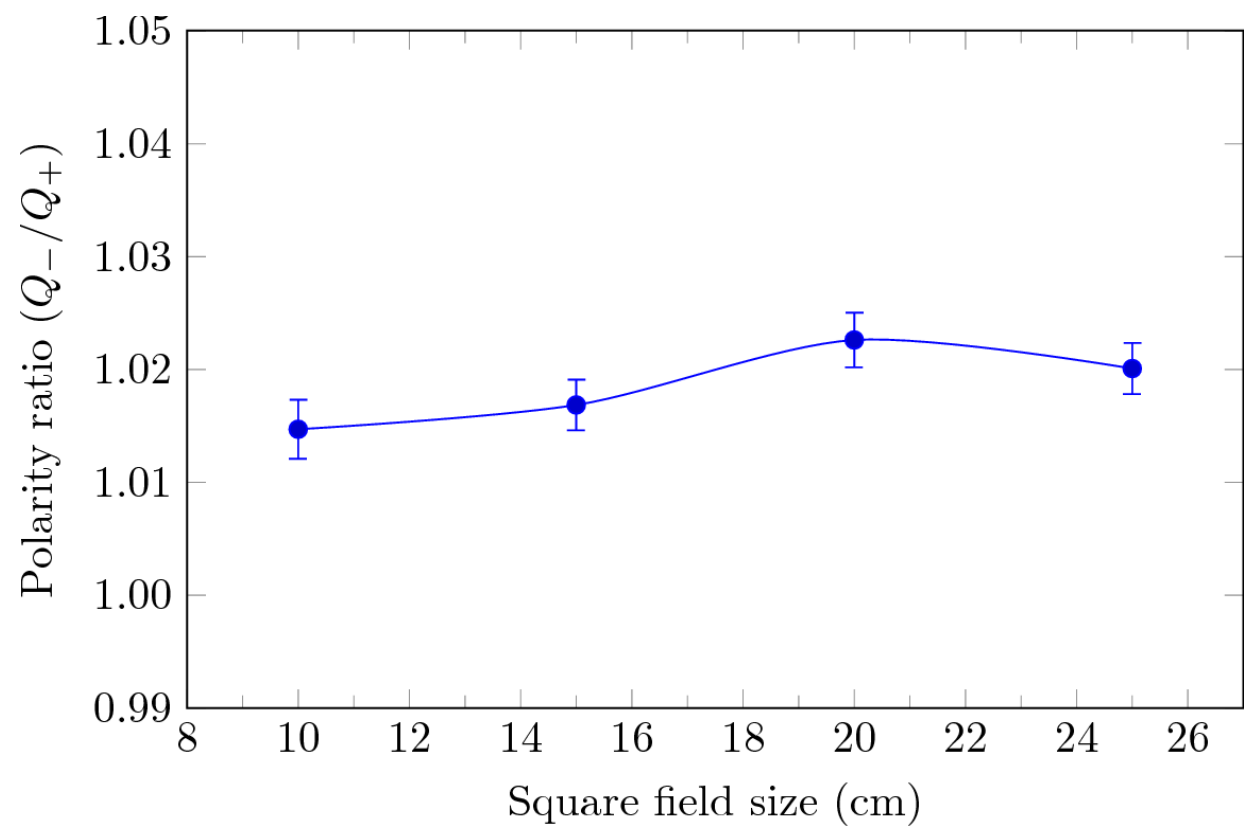




\section{CONCLUSION}

A dedicated plane parallel ionization chamber was characterized in clinical electron beams of $7 \mathrm{MeV}$ in terms of linearity of the response with absorbed dose, angular dependence, field size dependence and the polarity effect with the field size. The dedicated ionization chamber presented a linear response with the absorbed dose in a large dose range. The ionization chamber angular dependence was within international recommendations of $\pm 1 \%$ for $\pm 5^{\circ}$. It is sensitive to the scattered radiation increase due to changes in the field size, in accordance with an expected output factor curve. Polarity effects related to the change in radiation field size are present, but its behavior is similar to that of commercial ionization chambers. From the results obtained, it is possible to conclude that the ionization chamber tested in this work presents potential use for electron beam dosimetry in clinical routine.

\section{ACKNOWLEDGMENT}

The authors are thankful to the Brazilian agencies CNPq (Project 301335/2016-8), FAPESP (Project 2008/57863-2) and MCTIC (Project INCT for Radiation Metrology in Medicine, 573659/2008-7), for partial financial support.

\section{REFERENCES}

[1] d'ERRICO, F. Dosimetric issues in radiation protection of radiotherapy patients. Radiat Prot Dosim, v. 118, p. 205-212, 2006.

[2] MUIR, B. R.; McEWEN, M. R. Technical note: On the use of cylindrical ionization chambers for electron beam reference dosimetry. Med Phys, v. 44, n. 12, p. 6641-6646, 2017. 
[3] ALMOND, P. R.; BIGGS, P. J.; COURSEY, B. M.; HANSON, W. F.; HUQ, M. S.; NATH, R. AAPM's TG-51 protocol for clinical reference dosimetry of high-energy photon and electron beams. Med Phys, v. 26, n. 9, p. 1847-1870, 1999.

[4] IAEA - International Atomic Energy Agency. The use of plane-parallel ionization chambers in high-energy electron and photon beams: An international Code of Practice for dosimetry. IAEA TRS 381, Vienna: IAEA, 1995.

[5] IAEA - International Atomic Energy Agency. Absorbed dose determination in external beam radiotherapy: An international code of practice for dosimetry based on standards of absorbed dose to water. IAEA TRS 398, Vienna: IAEA, 2000.

[6] PEARCE, J.; THOMAS, R.; DuSAUTOY, A. The characterization of the Advanced Markus ionization chamber for use in reference electron dosimetry in the UK. Phys Med Biol, v. 51, n 3, p. 473-483, 2006.

[7] GERBI, B. J.; KHAN, F. M. The polarity effect for commercially available plane-parallel ionization chambers. Med Phys, v. 14, n. 2, p. 210-215, 1987.

[8] HAVERCROFT, J. M.; KLEVENHAGEN, S. C. Ion recombination corrections for planeparallel and thimble chambers in electron and photon radiation. Phys Med Biol, v. 38, n. 1, p. 25-38, 1993.

[9] NONATO, F. B. C.; SAKURABA, R. K.; da CRUZ, J. C.; CHIARA, A. C. M.; VERNUCIO, S. L.; MENEGUSSI, G; CALDAS, L. V. E. Development and characterization tests of a homemade ionization chamber with silver collecting electrode for use in electron beams. Biomed Phys Eng Express, v. 2, n. 1, p. 015011, 2016.

[10] NONATO, F. B. C.; SAKURABA, R. K.; da CRUZ, J. C.; CALDAS, L. V. E. Characterization tests of a new parallel plate ionization chamber for use in electron beams. Radiat Phys Chem, v. 104, p. 244-247, 2014.

[11] SILVA, J. O.; NONATO, F. B. C.; CALDAS, L. V. E. Characterization tests of a homemade ionization chamber in mammography standard radiation beams. Radiat Phys Chem, v. 95, p. 151-153, 2014. 
[12] PERINI, A. P.; NEVES, L. P.; FERNADEZ-VAREA, J. M.; CASSOLA, V. F.; KRAMER, R.; KHOURY, H. J.; CALDAS, L. V. E. A new parallel-plate graphite ionization chamber as a ${ }^{60}$ Co gamma radiation reference instrument. Radiat Phys Chem, v. 95, p. 106-108, 2014.

[13] NEVES, L. P.; PERINI, A. P.; CALDAS, L. V. E. Development and characterization of a new cylindrical ionization chamber for dosimetry of ${ }^{60} \mathrm{Co}$ beams. IEEE Trans Nucl Sci, v. 60, p. 712-715, 2013.

[14] PEARCE, J.; THOMAS, R.; DuSAUTOY, A. The caracterization of the Advanced Markus ionization chamber for use in reference electron dosimetry in the UK. Phys Med Biol, v. 51, p. 473-483, 2006.

[15] IAEA - International Atomic Energy Agency. Calibration of reference dosimeters for external beam radiotherapy. IAEA TRS 469, Vienna: IAEA, 2009.

[16] IEC - International Electrotechnical Commission. Medical electrical equipment Dosimeters with ionization chambers as used in radiotherapy. IEC 60731, Brussels: IEC, 2011.

[17] YOSHIZUMI, M.; CALDAS, L. V. E. A new ring-shaped graphite monitor ionization chamber. Nucl Instrum Meth Phys Res A, v. 219, n. 1, p. 207-210, 2010.

[18] NONATO, F. B. C. Design, construction and characterization of reference systems for electron beams of clinical accelerators. PhD thesis. Universidade de São Paulo, 2014. (In Portuguese)

[19] JCGM - Joint Committee for Guides in Metrology. Evaluation of measurement data Guide to the expression of uncertainty in measurement. JCGM 100:2008, Paris: JCGM, 2008.

[20] RAMSEY, C. R.; SPENCER, K. M.; OLIVER, A. L. Ionization chamber, electrometer, linear accelerator, field size, and energy dependence of the polarity effect in electron dosimetry. Med Phys, v. 26, n. 2, p. 214-219, 1999. 
[21] WILLIAMS, J. A.; AGARWAL, S. K. Energy-dependent polarity correction factors for four commercial ionization chambers used in electron dosimetry. Med Phys, v. 24, n. 5, p. 785-790, 1997. 